\title{
“Islas en el Atlántico": El Ámbito 0 en la ampliación del Museo de Historia y Antropología de Tenerife (Sede Lercaro)
}

\author{
Jesús Roberto Duque Arimany \\ Técnico Superior Museo de Historia y Antropología \\ http://doi.org/10.31939/bierehite/2019.01
}

Buenos días a todos. Una vez hecha las preceptivas y protocolarias presentaciones, expondremos ahora la filosofía del proyecto BIEREHITE y el contenido concreto de las jornadas que hoy nos ocupan.

En primer lugar, indicaremos que BIEREHITE, proyecto iniciado en el año 2010, es el acróstico de Bienes Relevantes para la Historia de Tenerife. Su objetivo es hablar de algún episodio o periodo de la historia de Tenerife y, por extensión, de Canarias, a partir de la exposición de un bien cultural que permita contextualizar dicho periodo. Cuando hablamos de bien cultural, consideramos que no debemos quedarnos en lo que es la parte anecdótica y es por ello por lo que, con vistas a que el proyecto tuviera una solidez teórica, creímos oportuno profundizar en la teoría del bien cultural desarrollada en la década de los sesenta del siglo pasado por el célebre administrativista italiano, Massimo Severo Giannini'. Hay que tener

\footnotetext{
1 Ha sido el profesor Juan Manuel Alegre Ávila, ponente en las primeras jornadas de patrimonio BIEREHITE, quien ha dado a conocer en el ámbito español la teoría de los bienes culturales desarrollada por Giannini que los definió como la "testimonianza materiale avente valore di civiltá", esto es, como testimonio material dotado de un valor de civilidad. En Juan Manuel Alegre Ávila (1994), Evolución y régimen jurídico del patrimonio histórico, tomo I, 645.
} 
en cuenta que la expresión de bien cultural ha sido legalmente utilizada por el Derecho Internacional, más particularmente en los convenios y recomendaciones de la UNESCO, pero, a veces, se olvida cuál fue el origen de este concepto siendo el referido Giannini, quien definió el bien cultural como aquel que reflejaba la existencia de una civilización, tanto en el ámbito público como en el privado².

Esta definición, aparentemente simple, rompía con la ortodoxia imperante en la materia. En primer lugar, porque ponía fin al concepto del Patrimonio Histórico en base a una concepción puramente estética. Y, en segundo lugar, porque proponía que el patrimonio privado, aun respetándose su titularidad, debería darse a conocer a la sociedad. Los parámetros expuestos por Giannini, base teórica de la "Comisión Francescini"3, favorecieron la revalorización de un patrimonio hasta aquellos momentos ninguneado, el patrimonio industrial y el patrimonio inmaterial, pues las manifestaciones que ponían de relieve la existencia de una civilización no entendían ni de divisiones ni de clasificaciones.

En realidad, los postulados de Giannini vienen a ser la adaptación jurídica de los planteamientos propuestos, en 1936, por Walter

2 El citado Alegre Ávila nos remite a la "Comisión Franceschini", la cual determinó al respecto que "Todo propietario de un bien cultural formalmente declarado está sujeto a cinco obligaciones: custodia, mantenimiento, no alteración de su estado físico, no utilización de manera perjudicial, permitir el goce público". En Juan Manuel Alegre Ávila (1994), Evolución y régimen jurídico del patrimonio histórico, tomo I, 259.

3 Por ley n 310, de 26 de abril de 1964, se instituyó una comisión de investigación que estableciera unas premisas de cara a la tutela y la valorización de las cosas de interés histórico, arqueológico, artístico y paisajjístico. Lo resultados de dicha comisión, la Relazione della Commissione d'indagine, fue publicada en 1966 por la Rivista Trimestrale di Diritto Pubblico. En palabras de Alegre Ávila "constituye, sin duda, la citada Relazione, un documento de inestimable trascendencia en el sector del patrimonio histórico, artístico, arqueológico y paisajístico [...] por suponer el punto de inflexión de la política italiana de los bienes culturales [...] y de una mayor y más profunda reflexión de la doctrina de este ámbito, reflexión que alcanzó su proyección dogmática más acusada en la construcción de la teoría de los bienes culturales". En Juan Manuel Alegre Ávila (1994), Evolución y régimen jurídico del patrimonio histórico, tomo I, 250-251. 
Benjamin en La obra de arte en la era de la reproductibilidad técnica4. Obra harto compleja y revolucionaria para la época, pone de relieve su enfrentamiento teórico con Theodor Adorno ${ }^{5}$, al que acusaba de ser incapaz de salir de su rígida posición -esto es, la defensa del "aura" del arte, incompatible con la producción industrial de los nuevos tiempos, véase el Cine y la música escrita para el Cine-. Sin lugar a dudas, Walter Benjamin anticipó todos estos fenómenos y Giannini los procesó y los incorporó a la legislación construida para reglar el patrimonio histórico.

Lo dicho afecta sobremanera a los objetos expuestos en los museos, pues la divulgación inherente a dichas instituciones entronca con los postulados de Benjamin y Giannini: divulgar y dar a conocer el patrimonio a toda costa, independientemente de su naturaleza pública o privada y de su "tipología” patrimonial. El Organismo Autónomo de Museos y Centros del Cabildo de Tenerife es un organismo autónomo administrativo creado para gestionar con eficacia el servicio público de uso público de los museos de Tenerife, a los que se atribuye un carácter insular, debido a la naturaleza de la institución a la que pertenecen. Atendiendo a las funciones que se le atribuyen en el actual Estatuto de Autonomía de Canarias (2018), en base a lo dispuesto en el artículo 65.2, "Los Cabildos Insulares son instituciones de la Comunidad Autónoma de Canarias"; y en el

\footnotetext{
4 Benjamin, como Giannini posteriormente, considera que la obra de arte no solo es estética y defiende que las artes artesanales, véase el Cine, son igualmente válidas, a pesar de la pérdida de aura. Al respecto dice Benjamin, “... en la época de la reproducción técnica de la obra de arte lo que se atrofia es el aura de ésta. El proceso es sintomático; su significación señala por encima del ámbito artístico. Conforme a una formulación general: la técnica reproductiva desvincula lo reproducido del ámbito de la tradición. Al multiplicar las reproducciones pone su presencia masiva en el lugar de una presencia irrepetible [...] La época de su reproductibilidad técnica desligó al arte de su fundamento cultural: y el halo de su autonomía se extinguió para siempre. Se produjo entonces una modificación en la función artística que cayó fuera del campo de visión del siglo [XIX]. E incluso se le ha escapado durante tiempo al siglo XX, que es el que ha vivido el desarrollo del Cine [...] Ya vemos que en el fondo se trata de la antigua queja: las masas buscan disipación, pero el arte reclama recogimiento". En Walter Benjamin (1989), Discursos Interrumpidos, 3-18.
}

5 Theodor W. Adorno y Hanns Eisler (1981), El cine y la música. 
65.3, "Los Cabildos Insulares constituyen órganos de gobierno, representación y administración de cada isla", por tanto, como "instituciones de la Comunidad Autónoma de Canarias", los museos adscritos a los cabildos se convierten en piezas clave en la cadena del patrimonio insular y regional.

A continuación, vamos a centrarnos en el tema que hoy nos congrega, "Islas del Atlántico". El título en cuestión alude al ámbito que en el futuro queremos implementar donde hoy se encuentra el ámbito 0 , el cual responde al título de "La mitología”.

Para ello, nuestro punto de partida ha sido el expositor luminoso vertical del referido ámbito 0 , un extraordinario ejercicio de síntesis pero que, a nuestro juicio, Lleva a confusión. La mitología griega y romana en el mismo representada, de pronto muestra una proyección de Müller elaborada en base a las descripciones habidas en los textos de Pomponio Mela. Este último autor es una fuente histórica real y poco tiene que ver, entonces, con las manifestaciones vinculadas a la mitología que en dicho panel se quieren representar. No obstante, este panel refleja muy a las claras, lo que ha sido una nebulosa absoluta en base a las constantes misceláneas planteadas entre la mitología y la realidad o, lo que es lo mismo, entre las fuentes literarias y las fuentes históricas. No en vano, nada más y nada menos que Theodor Mommsen en su Historia de Roma, clásico entre los clásicos, hace alusión a la entelequia que siempre ha supuesto Canarias para todos aquellos que han querido aproximarse a la Antigüedad Clásica. Nos dice Mommsen que: "De lo que refieren los historiadores de una expedición etrusca dirigida hacia las islas Canarias, y a la que los cartagineses estorbaron el paso. Verdadero o falso, el relato tiene su importancia característica..." 6 . Si Mommsen en aquellos momentos reflejaba este desconocimiento sobre el Archipiélago Canario, emitiendo hipótesis no contrastadas sobre

6 Theodor Mommsen (1962), Historia de Roma, tomo I, 197. 


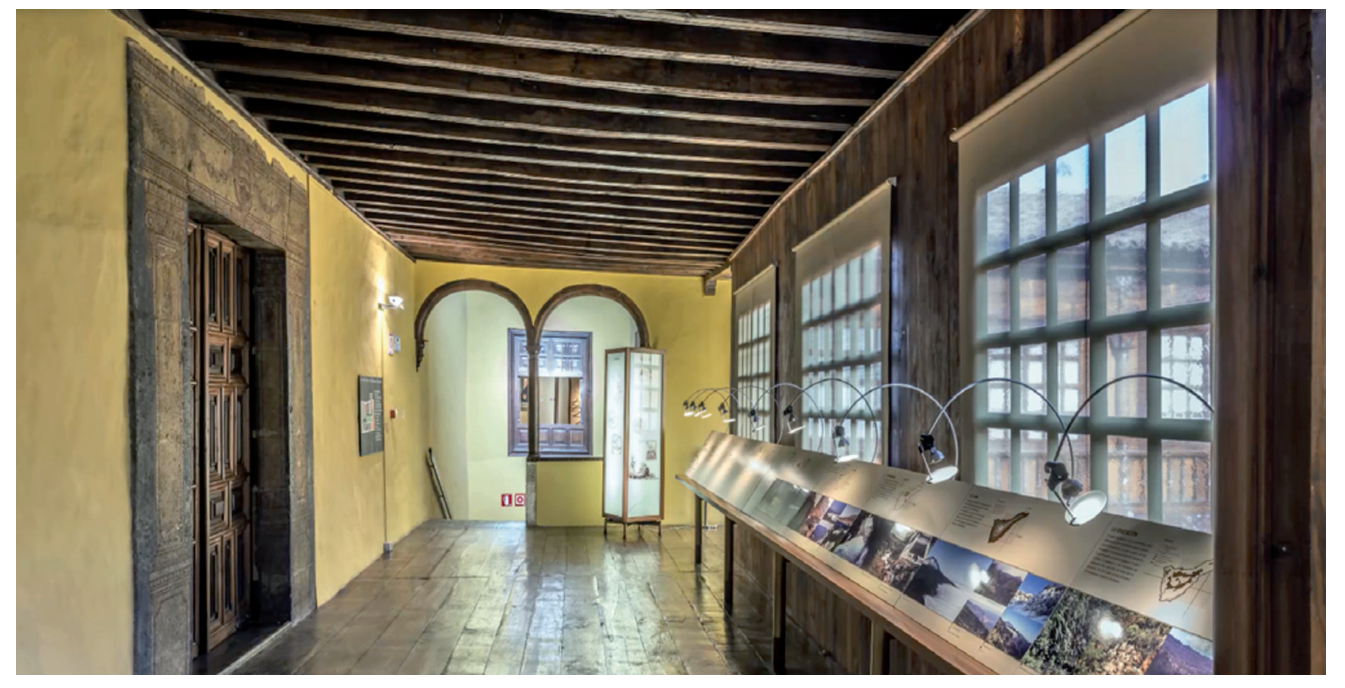

Fig. 1. Actual ámbito 0 de Lercaro.
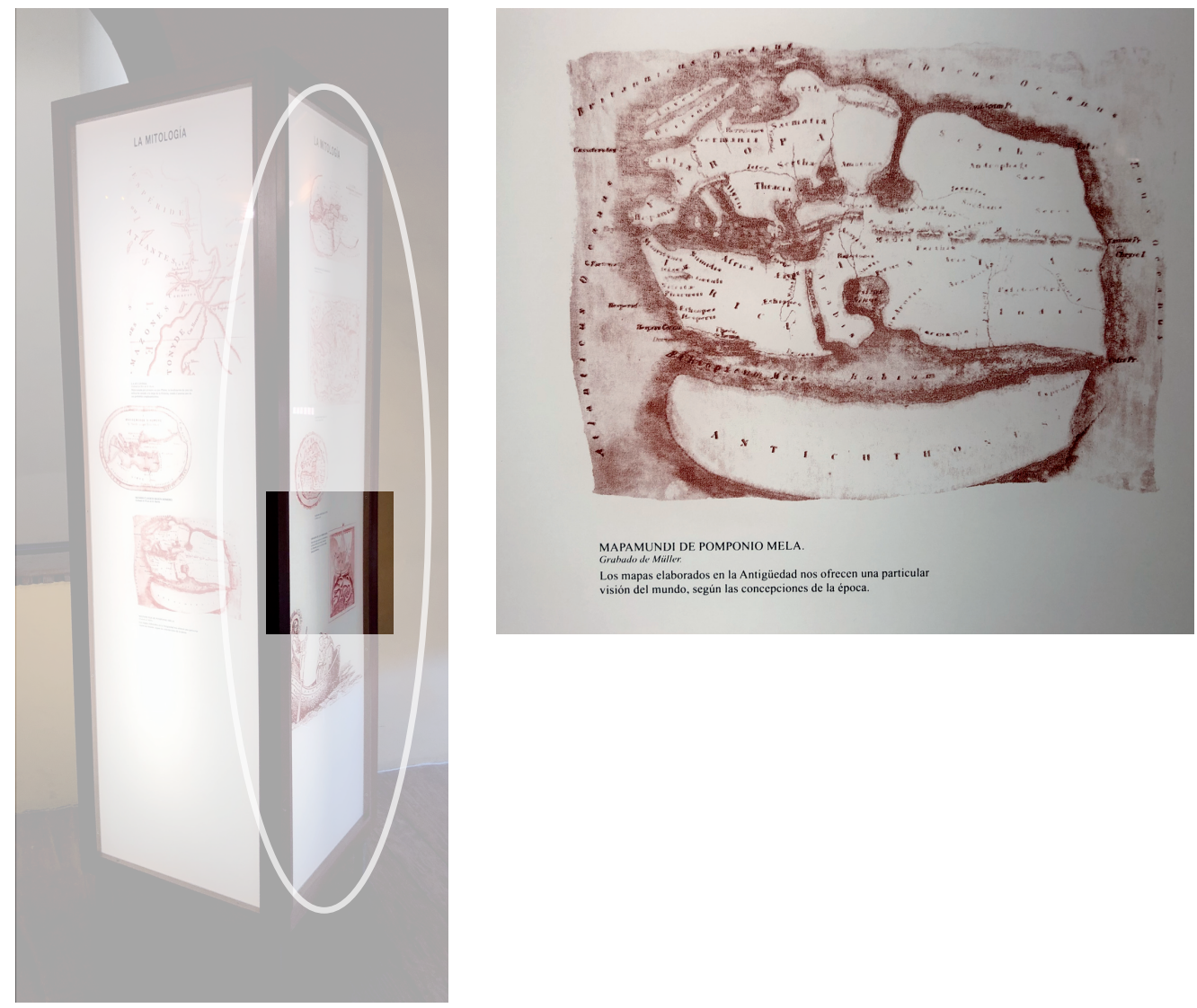

Figs. 2 y 3. Expositor y detalle, actual ámbito 0, Lercaro. 
el mismo ¿Por qué, entonces, no plantear la cuestión como un enfrentamiento entre Virgilio y Plinio el Viejo, con vistas a desmitificar el planteamiento virgiliano pero sin olvidar que siempre permaneció en el imaginario colectivo? Es este el motivo por el que hemos concebido el futuro ámbito 0 de la exposición permanente del Museo de Historia y Antropología (sede Lercaro) como un desarrollo del tema "Virgilio versus Plinio... desmitificando las fuentes pseudohistóricas".

Virgilio, en sus Bucólicas, implanta las bases para crear, en el imaginario colectivo de la Roma de Augusto, el mundo rural que, no nos engañemos, no es el real, sino, más bien al contrario, se trata de una idealización que procede, a su vez, de la Arcadia de Teócrito, una región que existiendo realmente, se convierte en el paradigma, ya en el siglo III a. C., para la creación de la ficción del género bucólico -una literatura de gabinete-, que tan bien reflejan los extraordinarios frescos del antiguo triclinio de la Villa de Livia en Prima Porta, que hoy pueden contemplarse en el Museo Nacional Romano (Palazzo Massimo alle Terme, Roma).

La paradoja de todo ello es que, habiéndose confirmado una presencia romana real en la isla de Lobos (circa siglo I a.C. - siglo I d.C.), tal como han demostrado las últimas excavaciones realizadas en aquel lugar, aquel hecho parece que no cambió en demasía la idea del paraíso que sobre las Islas Canarias se había implantado en el imaginario colectivo, idea que perduró en la mente de los más diversos poetas y artistas hasta bien entrado el siglo XIX. No en vano muchos fueron los viajeros llegados a Canarias que revelaron este punto de vista?

7 A este especto indica Carmelo Vega que los Stone "se entusiasman con el paisaje de las islas, dejándose llevar fácilmente, en algunos momentos, por la evocación de cier- 
En cualquier caso, las islas Canarias y su vinculación a la Antigüedad Clásica y, de manera muy especial, a la Roma imperial, siempre estuvieron presentes en el imaginario colectivo e, incluso, por sorprendente que pudiera parecer, en el jurídico. Tal fue el caso de las conocidas por la historiografía como "alegaciones de Alfonso de Cartagena", las cuales tuvieron lugar en Basilea, en 1436. En aquel momento, el prestigioso jurista al servicio de la corona española, frente a las pretensiones de Portugal por hacerse acreedor de la titularidad de las Islas Canarias, argumentó que para las Canarias, territorio no desconocido, no existía otro título aplicable que el derecho de "vecindad" o "proximidad", y por este mismo motivo, las Canarias deberían pertenecer a Castilla, pues habían sido heredadas por sucesión universal de la monarquía goda desde el tiempo de la dominación de la Mauritania Tingitana, por los vándalos y demás sucesores de los romanos ${ }^{8}$.

El inmenso ingenio jurídico de Alfonso de Cartagena no debe hacernos perder de vista nuestro principal argumento. Hablamos del bucolismo virgiliano pues, no por casualidad, el gran poeta latino, el hombre que una vez fue elegido por Octavio Augusto para "inventar" la historia de Roma en obras como la "Eneida", fue el protagonista elegido por Dante Alighieri para que le guiase, en su Comedia, desde el infierno al paraíso, pasando por el purgatorio. La literatura dantesca, muy a menudo concebida como el origen de la literatura italiana moderna, no deja de ser un "revival" del mito de lo exótico a la vez que un deseo del urbanita por evadirse a lugares idílicos, imposibles de encontrar incluso en las zonas rurales más próximas a aquel anhelo.

tos mitos sobre la naturaleza canaria (paraíso, fortuna, abundancia, etc.". En Carmelo Vega de la Rosa (1994), "Viaje fotográfico a un archipiélago inédito: las imágenes de J. Harris Stone para el libro Tenerife and its six satellites (1887)", XI Coloquio de Historia Canario - Americana, vol. 2, 402.

8 Los aspectos jurídicos de estas alegaciones, en concreto, los relacionados con el derecho de vecindad, han sido estudiados por Antonio Pérez Vouturiez (1958), Problemas jurídicos internacionales de la conquista de Canarias, 95, 97. 
En realidad, el Virgilio de Dante Alighieri es un ilustre precedente de la teoría del cronotopo histórico desarrollada por Mijail Bajtin?. Compleja donde las haya, podría sintetizarse indicando que, ante todo, estamos ante un sorprendente ejercicio de narcisismo por parte de las sociedades urbanitas, "superiores" culturalmente, que buscaban en las sociedades más primitivas un referente del arcaísmo al que idealizaban, porque aquel anhelado bucolismo tampoco existía en aquellas regiones más rurales a las que viajaban. En definitiva, nos estamos refiriendo a la mirada de "los otros", planteamiento sobre el que se sustentará el futuro ámbito 1 de la exposición permanente del museo, "El Atlántico en una Isla", en la que se pondrá de manifiesto cómo los viajeros que llegaron a Canarias desde el siglo XVI, muestran un desdén más que evidente hacia la emergente cultura criolla y, únicamente, tenían ojos para el exotismo inherente a la botánica y de la fauna, incluyendo en esta última, al guanche. Fue el autor del proyecto de ampliación del MHA len la sede Lercaro), Fernando Estévez, quién planteó una revisión de la historia de Canarias incorporando los postulados de Bajtin.

Los planteamientos de Bajtin marcan el punto y final de aquellos postulados virgilianos del género bucólico. Pero, frente a estos bien es cierto que, desde los primeros tiempos del Imperio Romano, o incluso ¿desde finales de la República?, Roma ya conocía a la Canarias real, al Archipiélago, o parte de él, concebido como un accidente geográfico. El reciente descubrimiento del yacimiento de la Isla de Lobos, no deja duda alguna al respecto. Abandonamos definitivamente al gran Virgilio y nos acercamos ahora a Plinio el Viejo. A este general romano, que falleció, según el testimonio de su hijo, en la erupción del Vesubio que sepultó Pompeya, lo hemos utilizado como paradigma del autor fiable, esto es, una fuente historiográfica de primer nivel en base al libro VI de su Historia Naturalis, pero, desde luego, no es el único.

9 Mijail M. Bajtin (1989), Teoría y estética de la novela, 273-409. El concepto al que aludimos se encuentra desarrollado, especialmente, en el capítulo que lleva por título "Las formas de tiempo y del cronotopo en la novela. Ensayos de poética histórica". 
La historiografía más reciente sitúa a nuestro erudito en una corriente de autores entre los que también se encuentran Pomponio Mela, Plutarco e, incluso, Arnobio. Todos ellos tienen en común que toman como referencia el viaje de Juba II de Mauritania (50 a.C. -23 d. C.), descrito en el Tratado sobre Libia (6d.C.), y el de Estacio Seboso. Para todos estos autores, las Islas Canarias no son solamente Fuerteventura y Lanzarote. Pero, ¿Quién argumentaba lo contrario? Para responder a esta cuestión debemos remitirnos a otra familia de fuentes, en este caso la integrada por los relatos de Posidonio, Salustio, Plutarco y Estrabón, pues todos estos autores toman como referencia el viaje de Eudoxio de Cícico IC. 150 a. C. 100 a. C.). A diferencia de los postulados de Arnobio, en opinión de todos ellos, dos de las islas Canarias, Fuerteventura y Lanzarote, eran las Islas Hespérides ${ }^{10}$.

En cualquier caso, todas estas fuentes corroboran el conocimiento que tenía Roma sobre las Islas Canarias en el periodo compren-

dido entre el siglo I a.C y el siglo I d.C. Y, paulatinamente, la fecha de la romanización ha sido ratificada por la arqueología.

En primer lugar, debemos hacer alusión a la denominada "piedra Rosetta de Canarias". Localizada en Fuerteventura, nos revela que los pueblos bereberes trasladados a Canarias -Lanzarote, Fuerteventura, Gran Canaria, El Hierro y Tenerife- dejaron su impronta en forma de escritura latino-canaria, la cual aprendieron como consecuencia de la romanización del norte de África que afectó a las poblaciones bereberes. En líbico latino, la inscripción de la piedra debe traducirse como "hijo de Makuran y de Timamasi, hija de

10 Hemos tomado esta clasificación de familias de fuentes históricas de Trinidad Arcos Pereira y Antonio Santana Santana, “Las dos islas Hespérides atlánticas (Lanzarote y Fuerteventura, Islas Canarias, Españal durante la Antigüedad: del mito a la realidad”, Gerión, 24, 1, 85-110. 
Timamasi"; mientras que, en líbico bereber debe traducirse como "hijo de Makuran"11.

La cronología de la "Rosetta de Canarias" coincide con la expuesta en la teoría de las deportaciones, reivindicada en su momento por Juan Álvarez Delgado y continuada hasta nuestros días, entre otros, por el profesor Antonio Tejera Gaspar ${ }^{12}$ y José Juan Jiménez González ${ }^{13}$. Como en las tesis expuestas anteriormente, se circunscribe el momento del contacto entre Roma y Canarias entre finales de la República y el comienzo del Imperio Romano.

Finalmente, nos referiremos al taller de púrpura encontrado en la isla de Lobos. En el año 2012, un hallazgo casual dio a conocer un yacimiento en el que aparecieron numerosos ejemplares del molusco conocido como Stramonita Haemastoma, así como objetos varios asociados a las tradicionales labores de los trabajadores de

11 Recientes han sido en Canarias los estudios sobre la escritura latino - canaria. Véase María Antonia Perera Betancort y José Juan Jiménez González (2016), “La cumbre escrita. El Cuchillete de Buenavista”, XVI Jornadas de Estudios de Fuerteventura y Lanzarote, también José Farrujia et al. (2009), “Las escrituras líbico bereber y latino canaria en la secuenciación del poblamiento de las Islas Canarias", El Museo Canario, 9-50. En esta última publicación citada, bien es cierto que se habla de una primera oleada de población, en torno al siglo VI a.C.

12 Indica Tejera Gaspar que "el testimonio de los cronistas - historiadores de Canarias sobre el castigo infligido por los romanos a las poblaciones magrebíes y su posterior destierro a estas islas, tiene asimismo su confirmación en las penas a que eran sometidos quienes cometían un acto de alta traición al poder de Roma, según se recoge en su jurisprudencia, compilada en el Digesto del emperador Justiniano (527-565), Digesta lustiniani Augusti". Véase Antonio Tejera Gaspar et al. (2006), Canarias y el África Antigua, 87. El profesor Tejera Gaspar sostiene que las deportaciones a Canarias, se hicieron en torno a la era cristiana, pero no deja de reconocer la veracidad de, al menos, un fragmento del conocido como "Periplo de Hanón”, en concreto su célebre párrafo 8, en virtud del cual los cartagineses no llegaron a Canarias pero sí a Cerne, esto es, uno de los islotes de Mogador. Sobre esta última cuestión véase Antonio Tejera Gaspar et al. (2006), Canarias y el África Antigua, 43.

13 José Juan Jiménez González (2005), Canarii. La génesis de los canarios desde el Mundo Antiguo. 
la púrpura. En la publicación ${ }^{14}$ editada sobre las investigaciones realizadas en dicho yacimiento se habla del potencial uso de venenos para la pesca, tal como lo narraron en su tiempo Plinio el Viejo y otros autores contemporáneos. A ello hay que añadir la comprobación de la ejecución del marisqueo en mano, la presencia de yunques líticos con cráteres, la aparición de un fragmento de un posible caldero de plomo con adherencias indicando una más que probable extracción y producción de tinte en este lugar. Todas las pruebas concluyen que estamos ante un a taller de púrpura, seguramente estacional. No obstante, no ha podido concluirse si este taller quedó en fase experimental o si, por el contrario, llegó a consolidarse como uno más entre los múltiples existentes en el denominado "Círculo del Estrecho". En la instalación procesual paralela a estas jornadas tendremos la oportunidad de contemplar algunas de las manifestaciones materiales más destacadas de este yacimiento.

Sobre algunas de estas cuestiones nos aportarán su conocimiento las profesoras Trinidad Arcos y Carmina del Arco Aguilar. La primera sobre la reinterpretación de los textos -especialmente los referidos a la navegación de aquella época y al modus operandi de Roma en aquellos momentos: ¿Tenía Roma necesidad de venir a Canarias antes del siglo I de nuestra era? Y si así fue, ¿Cuáles eran aquellas rutas? La segunda acerca del yacimiento de Lobos, en uno de los seminarios adscritos a esta edición de las jornadas de patrimonio BIEREHITE.

El ámbito cronológico objeto de estas jornadas, siglo I - XV, nos impide ahora hacer un análisis más exhaustivo sobre qué pudo suceder antes del siglo I, pero siendo Plinio nuestra fuente de re- 
ferencia, es inevitable retrotraernos al viaje de Juba y, por consiguiente, al tan debatido periplo de Hanón el cartaginés.

En el futuro ámbito de la exposición permanente, "Islas en el Atlántico", igualmente queremos dejar constancia de uno de los viajes más relevantes de toda la historia de Canarias. Nos referimos en esta ocasión al "redescubrimiento" de las Islas Canarias en una expedición capitaneada, en 1339, por el genovés Lancelotto Malocello. Ya Serra Ráfols había adelantado la veracidad de dicha expedición, ateniéndose a la existencia en la Biblioteca Nacional de Francia del célebre portulano de Angelino Dulcert, en el que aparece escrito el nombre de la isla de Lanzarote en honor a su insigne "descubridor". Pero ha sido Alberto Quartapelle, en un artículo publicado en la Revista de Historia, "El redescubrimiento de las Islas Canarias en el anno Domini, 1339"15, quien ha confirmado la fecha exacta del viaje, corrigiendo las indefiniciones al respecto planteadas por el ya citado Elías Serra Ráfols. El estudio, entre otras cuestiones, revela detalles tan curiosos como que los topónimos del célebre portulano conservado en Francia, están escritos en dialecto ligur y que, otro portulano elaborado escasamente unos años después, conservado en la Biblioteca Nacional Británica, presenta sus topónimos en dialecto mallorquín. ¿Podría hablarse entonces de una expedición mallorquina - genovesa? No es de extrañar, pues, como ha señalado en alguna de sus publicaciones otro ilustre historiador que nos acompañará en estas jornadas, David Abulafia, la figura del genovés naturalizado mallorquín durante este periodo era un hecho más que común. Si ello fuera así, entonces el viaje de Malocello, podría considerarse un antecedente directo de la evangelización por parte de mallorquines en Gran Canaria, véase el episodio del testamento de los 13 frailes rememorado en Le Canarien.

15 Alberto Quartapelle (2017), “El redescubrimiento de las Islas Canarias en el anno domini 1339", Revista de Historia Canaria 199, 11-37. 
Otro episodio que pretendemos ilustrar en el futuro ámbito "Islas en el Atlántico" es el resultado de una cuestión que, consideramos, es más que obligada plantearse. Deberíamos preguntarnos, situándonos en el periodo comprendido entre la caída del Imperio Romano y el "redescubrimiento" de Malocello.... ¿Qué sucedió en Canarias? ¿Es cierto que, al dejar de existir el Imperio Romano de Occidente, las Islas Canarias cayeron en el mayor de los ostracismos? Aunque, bien es cierto que no hay pruebas concluyentes que evidencien lo contario hasta la fecha, cuesta creer que un territorio que, como ya hemos visto, fue visitado y conocido por Roma, dejara de existir para el mundo desde el siglo $V$ de nuestra era y no fuera "redescubierto" hasta, aproximadamente, nueve siglos más tarde.

Anteriormente, ya hemos aludido a las ingeniosas alegaciones del insigne Alfonso de Cartagena y su conocimiento de las vinculaciones de las Islas Canarias con la Mauritania Tingitana romana y la de sus herederos, vándalos, godos, etc. Hay otra fuente, menos citada, pero no por ello menos válida. Tanto en el manuscrito $B$ como en el $G$ de Le Canarien, se inserta un curioso pasaje, "Cómo un fraile franciscano habla de las cosas que vio, con un libro que hizo de ellas", en el que se relata el viaje hasta llegar al reino del mítico Preste Juan: “... Y empezaremos cuando fue más allá de las Montañas Claras. Vino a la ciudad de Marruecos, que conquistó Escipión el Africano, que en la antigüedad se solía llamar Cartago, que era cabeza de toda África, y de allí vino al mar Océano, a Nifet, a Samor y a Safí, que están muy cerca del cabo Cantín, y después vino a Mogador, que está en otra provincia que se llama Gasul, y allí empiezan las Montañas Claras. Y de allí vino a dicha Gasul, que es un gran país lleno de riquezas y vino hacia la marina a un puerto que se llama Samateve, y desde allí al cabo de Non, que es viniendo a nuestras islas. Y allí se metió en el mar en una barca y vino al puerto de Saubrún y [siguió] toda la costa de moros que se llama las Playas Arenosas, hasta el cabo de Bojador que está a doce leguas de nosotros, y está en un reino que se llama Guinea. Y allí tomaron su camino para ir a ver y a estudiar las islas 
de esta banda. Y buscaron varios otros países, de los cuales no hacemos ninguna mención. Y el fraile se separó de ellos y se fue hacia Oriente por muchas regiones, hasta un reino que se llama Dongola que está en la provincia de Nubia, habitada por cristianos ly se llama Preste Juan, en uno de sus títulos, patriarca de Nubial, que está situada lindando por un lado con los desiertos de Egipto y por otro lado con el río Nilo, que viene de las provincias de Preste Juan, y se extiende el reino de Dongola [hasta allí] donde el río Nilo se separa en dos brazos, uno de los cuales forma el Río del Oro, que viene hacia nosotros, y el otro va a Egipto y entra en la mar en Damieta. Y desde aquellas regiones se fue el fraile a Egipto, a El Cairo, y en Damieta entró en una nave de cristianos y después volvió a Sarette, que está frente a Granada, y volvió por tierra a la ciudad de Marruecos y atravesó las Montañas Claras y pasó por Gasul. Y allí encontró moros que armaban una galera para ir al Río del Oro y contrató con ellos. Y entraron en la mar y mantuvieron la dirección del cabo de Non y del cabo Saubrún y después del cabo Bojador y toda la costa hacia el sur, hasta el Río del Oro...".

El relato en Le Canarien -tanto en el manuscrito B como en el Gdescribe un viaje más propio de tiempos anteriores. Es Jiménez de la Espada ${ }^{16}$ quien nos recuerda que el relato del Preste Juan insertado en Le Canarien está tomado por los redactores de la "crónica" normanda de la conquista de Canarias del Libro del conoscimiento (c. 1390), supuestamente escrito por un franciscano español, un texto cuyo relato se construye a partir de las observaciones de portulanos como el de Dulcert (1339) y Cresques (1375). El Preste Juan es citado por primera vez por Otón de Frisinga, obispo y cronista del siglo XII y, a partir de ese momento, es uno más en el imaginario colectivo de la época, como así lo acreditan su presencia en obras como Los Viajes de Marco Polo (1299), Los viajes de Sir John Mandeville (c. 1347), Embajada a Tamorlán de Ruy González de Clavijo

16 Marcos Jiménez de la Espada (1877), Libro del conoscimiento de todos los reynos e tierras e señoríos que son por el mundo e de las señales e armas que han cada tierra e 
(1406), Las Andanças de Pero Tafur (1439) y la Historia del Infante don Pedro de Portugal (c. 1450) ${ }^{17}$. Sorprendentemente, de entre todas las obras citadas, solo en el Libro del Conoscimiento se le ubica en Etiopía. En cualquier caso, el fragmento del Libro del Conoscimiento interpolado en Le Canarien nos ilustra sobre el saber existente en aquellos momentos sobre el mundo conocido y su plasmación en los portulanos y derroteros ${ }^{18}$ imbuidos en el espíritu de la tradición cultural resultante del contacto entre la civilización occidental y la islámica. ¿Es el Preste Juan del Libro del Conoscimiento un personaje concebido en tiempos de las Cruzadas? Dicho periodo, que siguiendo la tradición occidental se ha presentado habitualmente como el enfrentamiento maniqueo de cristianos frente a islámicos, en realidad se caracterizó por la supervivencia y, teniéndose en cuenta que tanto cristianos como árabes en realidad estaban divididos, era de lo más habitual que tantos unos como otros se unieran -islámicos y cristianos-. Aunque este planteamiento no es para nada novedoso, ha vuelto a ponerse de relieve en la obra de Amin Malouf, Las cruzadas vistas por los árabes ${ }^{19}$, una síntesis de tantas y tantas publicaciones existentes sobre esta materia. En opinión de

señorío por sy e de los reyes e señores que los proveen, escrito por un franciscano español a mediados del siglo XI. Jiménez de la Espada reconoció la existencia de tres manuscritos, utilizando para su edición el más antiguo. En 1944, Buenaventura Bonnet Reverón daba a conocer a la historiografía canaria las valiosísimas aportaciones de Jiménez de la Espada, y añadía la existencia de otros manuscritos: Un viaje del mundo, supuestamente escrito en 1305 y con notas del cronista de Aragón, Jerónimo de Zurita, a quien perteneció, y, finalmente, otro manuscrito más antiguo que los textos examinados por Jiménez de la Espada y que parece que fue el utilizado por el mismísimo Boutier para su composición de Le Canarien. Véase Buenaventura Bonnet Reverón (1944), "Las Canarias y el primer libro de geografía medieval, escrito por un fraile español en 1350". Revista de Historia 67, 205-227.

17 Sobre dicha relación de viajes véase Ana Belén Chimeno del Campo (2007), “El reino del Preste Juan y los viajeros en la Alta edad Media", Actas del XI Congreso Internacional de la Asociación Hispánica de Literatura Medieval, 424.

18 Es particularmente llamativo la existencia de un derrotero fechado en torno a 1404, y que fue utilizado por los normandos conquistadores de Canarias. En Juan Álvarez Delgado (1977), "Leyenda erudita sobre la población de Canarias con africanos de lenguas cortadas", Anuario de Estudios Atlánticos.

19 Amin Maalouf (2017), Las cruzadas vistas por los árabes. 
Malouf, el pueblo del profeta Alá había perdido, desde el siglo IX, el control de su destino ${ }^{20}$, pues prácticamente todos sus dirigentes eran extranjeros. De ahí que fuera habitual el enfrentamiento entre chíitas y suníes e, igualmente, que hubiera un auténtico galimatías entre kurdos, mamelucos y mogoles. Lo mismo podría decirse del bando de los "frany", esto es, los francos, tal como eran conocidos por los árabes. En este contexto, y siempre en búsqueda de la supervivencia, era más que necesario el contacto y el intercambio de información entre ambas civilizaciones y, desde luego, la cartografía fue uno de los elementos imprescindibles. La navegación árabe, en aquellos momentos, había adquirido un gran desarrollo y no es por casualidad, que viajeros como Al-Idrisi o Alfraganus -este último referente ineludible para el mismísimo Cristóbal Colón-, fueran la quinta esencia de los avances de la navegación a partir del comienzo del desarrollo de la brújula. Volvemos entonces a formular la pregunta ¿Pudo nacer el relato que aseguraba la presencia del Preste Juan en Etiopía en este contexto? La revisión de las crónicas de Ibn al Qalanisi, cronista de Antioquía, Ibn al-Atir, cronista de Damasco, Usama Ibn Muqidh, cronista de Damasco, Abul-Faray Basilio, cronista de la reconquista de Edesa, Kamal alDin, cronista de Alepo, Baha al-Din, biógrafo de Saladino, Abu Firas, cronista de la secta de "Los asesinos", Ibn Yubayr, cronista de Siria y Damasco en los tiempos de Saladino, Ibn Wasel, cronista de Siria y Abul-Fida, historiador de origen ayubí, cronista de los últimos momentos de los "frany", en Trípoli y Acre, nos han sugerido ${ }^{21}$ ahondar en este periodo. El desconocimiento del papel de los traductores en este momento de la historia es grande, aunque sí sabemos que durante las cruzadas, los árabes se esforzaron más por conocer el lenguaje de sus opuestos que sus opuestos del

20 El autor nos habla de un mundo árabe totalmente fragmentado desde los tiempos de las primeras cruzadas, situación de debilidad que es aprovechada por los occidentales para crear un principado de Antioquía, otro en Nicea, también en Jerusalén. Por ello no debe sorprendernos las constantes alianzas entre árabes y occidentales. Tal fue el caso del pacto establecido entre Firuz -enfrentado con el emir de Antioquía, Yaghi Siyan- y los sitiadores" frany" (francos) de la referida ciudad. En Amin Maalouf (2017).

21 Siempre siguiendo a Amin Maalouf (2017), Las cruzadas vistas por los árabes. 
suyo ${ }^{22}$. La profesora Maravillas Aguilar será la encargada de transmitirnos en su ponencia su conocimiento y particular visión sobre el mundo árabe en la Baja Edad Media.

Obviamente, Le Canarien igualmente será revisitado en este futuro ámbito, "Islas en el Atlántico". Al respecto nos platearemos si la expedición de Jean de Béthencourt fue un eco tardío del espíritu de las cruzadas, o si, al contrario, fue algo más. ¿Conocían los normandos la tradición de la fabricación de la púrpura existente en Canarias desde la Antigüedad? ¿El nombre de la villa de procedencia de Béthencourt, Grainville-la-tentuirére, es igualmente una casualidad? Le Canarien, tanto el manuscrito $G$ como el B, es un magnífico retrato del periodo de transición que se produce entre la Edad Media y Renacimiento, no siempre bien comprendido, habida cuenta de los estereotipos y clasificaciones académicas; y no cabe la menor duda de que la incomprensión es mucho mayor cuando se intenta vincular a Canarias con el mismo. En efecto, este periodo no hubiera sido posible entenderlo sin los pioneros estudios del profesor Miguel Ángel Ladero Quesada y posteriormente continuados por Eduardo Aznar Vallejo. Precisamente este último expondrá su particular visión al respecto en "Canarias en los orígenes de la civilización atlántica. La conquista del Océano".

Finalmente, el ámbito "Islas en el Atlántico", tiene como objetivo explicar la compleja misión evangelizadora. Desde al menos 1342 , somos conocedores de la presencia de aborígenes de Gran Canaria bautizados por carmelitas en Palma de Mallorca con la intención de utilizarlos como "lenguas", "trujamanes" o traductores, intención evangelizadora ratificada en la creación de aquel "Principado de la Fortuna"23, en 1344, un feudo papal en toda regla en manos

\section{Siempre siguiendo a Maalouf.}

23 Pérez Voituriez enumera las condiciones que en tiempos de Clemente VI, a su juicio, se dieron para constituir dicha figura: 1) Solemne investidura por la que se crea, ex 
de Luis de la Cerda. De todas las fuentes historiográficas, es curioso que solo Torriani se aventurara a afirmar que aquellos que estuvieron en Gran Canaria fueron frailes franciscanos mallorquines. Todas las demás fuentes aluden a mallorquines. Por lo tanto, ¿aquellos primeros moradores baleares eran beguinos, frailles 0 seglares? Sea como fuere, el inicio de la evangelización, primero por carmelitas y luego por franciscanos, es un proceso apasionante que ha llevado a algunos autores a hablar de "sincretismo" y a otros de "asimilación", siempre que han querido abordar el siempre complejo fenómeno de la aculturación. Sobre Gran Canaria, los conservadores del Museo de la Cueva Pintada de Gáldar, Carmen Gloria Rodríguez Santana y Jorge Onrubia Pintado, nos darán su particular visión al respecto. Sobre lo que aconteció en Tenerife más de un siglo después; será Sergio Baucells Mesa, quien expondrá cuestiones varias al respecto, entre ellas, la concerniente a la división existente entre la sociedad guanche antes ya de la conquista, la cual se vio acrecentada después de la misma, utilizando el paradigmático caso del célebre pleito de los descendientes de los guanches que querían seguir portando a la Virgen de Candelaria, hecho que les aseguraba un estatus de nobleza conforme a los parámetros de la nueva sociedad cristiana europea, pero que, inevitablemente, les alejaba de sus costumbres guanches.

La aculturación, del mismo modo, plantea otro debate que pretendemos quede plasmado en este nuevo ámbito de la exposición permanente del MHA-Lercaro, tan vigente en nuestros días. Nos referimos al planteamiento "genocidio versus etnocidio", debate que incluso ha sido trasladado al Parlamento de Canarias. Consideramos que, a tenor de los resultados obtenidos en las últimas

novo, un reino cristiano en tierra salvaje no conquistada; 2) Concesión de jurisdicción temporal, con la facultad de batir moneda, todos los demás derechos reales y el patronato de las iglesias y monasterios que construyese; 3) La Santa Sede se reserva el supremo dominio, constituyendo el designado reino un feudo del papa, con la obligación de prestarle el debido tributo; 4) En caso de incumplimiento de sus obligaciones, revendría la plena soberanía a la sede apostólica. En Antonio Pérez Voituriez (1958), Problemas jurídicos internacionales de la conquista de Canarias,77-78. 
investigaciones genéticas y, tras una exhaustiva revisión de las fuentes documentales, no hay duda alguna de que, tras la conquista, en Tenerife se gestó una cultura criolla -la cual pagó el peaje del etnocidio guanche- a la que apenas prestó atención el viajero europeo medio que pasaba por las Islas. 


\section{BIBLIOGRAFÍA}

Adorno, Theodor W. y Eisler, Hanns (1981), El cine y la música, Madrid, editorial Fundamentos.

Alegre Ávila, Juan Manuel (1994), Evolución y régimen jurídico del patrimonio histórico, Madrid, Ministerio de Cultura.

Álvarez Delgado, Juan (1977), “Leyenda erudita sobre la población de Canarias con africanos de lenguas cortadas", Anuario de Estudios Atlánticos, volumen $1, n^{0} 23$.

Arcos Pereira, Trinidad y Santana Santana, Antonio, "Las dos islas Hespérides atlánticas (Lanzarote y Fuerteventura, Islas Canarias, Españal durante la Antigüedad: del mito a la realidad", Gerión, 24, 1, 85-110.

Bajtin, Mijail M. (1989), Teoría y estética de la novela, Madrid, Taurus.

Benjamin, Walter (1989), Discursos Interrumpidos, Buenos Aires, Taurus.

Bonnet Reverón, Buenaventura (1944), "Las Canarias y el primer libro de geografía medieval, escrito por un fraile español en 1350", Revista de Historia 67, 205-227.

Chimeno del Campo, Ana Belén (2007), “El reino 
del Preste Juan y los viajeros en la Alta edad Media", Actas del XI Congreso Internacional de la Asociación Hispánica de Literatura Medieval, 423-429.

Del Arco Aguilar, María del Carmen et al. (2016), Un taller romano de púrpura en los límites de la Ecúmene. Lobos 1 (Fuerteventura-Islas Canarias). Primeros resultados. Organismo autónomo de Museos y Centros del Excmo. Cabildo Insular de Tenerife.

Farrujia, José et al. (2009), “Las escrituras líbico bereber y latino canaria en la secuenciación del poblamiento de las Islas Canarias", El Museo Canario, 9-50.

Jiménez de la Espada, Marcos (1877), Libro del conoscimiento de todos los reynos e tierras e señoríos que son por el mundo e de las señales e armas que han cada tierra e señorío por sy e de los reyes e señores que los proveen, escrito por un franciscano español a mediados del siglo XI, Madrid, Boletín de la Sociedad Geográfica Española.

Jiménez González, José Juan (2005), Canarii. La génesis de los canarios desde el Mundo Antiguo, Tenerife, Gobierno de Canarias y Centro de la Cultura Popular Canaria.

Maalouf, Amin (2017), Las cruzadas vistas por los árabes, Madrid, Alianza editorial.

Mommsen, Theodor (1962), Historia de Roma, Madrid, Aguilar. 
Perera Betancort, María Antonia y Jiménez González, José Juan (2016), “La cumbre escrita. El Cuchillete de Buenavista", XVI Jornadas de Estudios de Fuerteventura y Lanzarote.

Quartapelle, Alberto (2017), “El redescubrimiento de las Islas Canarias en el anno domini 1339", Revista de Historia Canaria 199, 11-37.

Pérez Vouturiez, Antonio (1958), Problemas jurídicos internacionales de la conquista de Canarias, Tenerife, Secretariado de Publicaciones de la Universidad de La Laguna.

Tejera Gaspar et al. (2006), Canarias y el África Antigua, Tenerife, Gobierno de Canarias y Centro de la Cultura Popular Canaria.

Vega de la Rosa, Carmelo (1994), “Viaje fotográfico a un archipiélago inédito: las imágenes de J. Harris Stone para el libro Tenerife and its six satellites (1887)", XI Coloquio de Historia CanarioAmericana, 2, 393-410. 